\title{
The antitumor activity of umbelliferone in human renal cell carcinoma via regulation of the $\mathrm{p} 110 \gamma$ catalytic subunit of PI3K $\gamma$
}

\author{
XUE WANG ${ }^{1,2}$ \\ SHUAISHUAI HUANG ${ }^{1,2}$ \\ XIA XIN ${ }^{1}$ \\ YU REN ${ }^{1,2}$ \\ GUOBIN WENG ${ }^{1,2, *}$ \\ PING WANG ${ }^{3}$ \\ ${ }^{1}$ Department of Urologic Surgery, \\ Ningbo Urology and Nephrology \\ Hospital, Ningbo 315000, China \\ ${ }^{2}$ Laboratory of Kidney Carcinoma, \\ Urology and Nephrology Institute of \\ Ningbo University, Ningbo 315000 \\ China \\ ${ }^{3}$ Ningbo University, School of \\ Medicine, Ningbo 315211, China
}

Accepted August 18, 2018

Published online September 18, 2018

\begin{abstract}
Umbelliferone exhibits extensive pharmacological activity, including anti-immunomodulatory, anti-inflammatory and antigenotoxicity activities. However, its antitumor properties still remain unclear in human renal cell carcinoma (RCC) cells. Our results have revealed that treatment of human RCC cells (786-O, OS-RC-2, and ACHN) with umbelliferone reduced cell proliferation in a concentration-dependent manner and induced dose-dependent apoptotic events. In addition, cell cycle analysis determined that umbelliferone treatment induced cell cycle arrest in the G1 phase in a dose-dependent manner. Furthermore, western blotting analysis showed a dose-dependent decrease in Ki67, MCM2, Bcl-2, CDK2, CyclinE1, CDK4, and CyclinD1 and a dose-dependent increase in Bax in RCC cells cultured with umbelliferone. Similarly, umbelliferone exhibited a dose-dependent reduction of p110 $\gamma$ when using western blotting analyses. Taken together, these results provide an insight into the pharmacology regarding the potential application of umbelliferone, which contributes to cell death by decreasing p110 $\gamma$ protein expression.
\end{abstract}

Keywords: umbelliferone, renal cell carcinoma, p110 $\gamma$, anticancer activity

Kidney cancer accounts for approximately $5 \%$ of all new cancer diagnoses. Renal cell carcinoma (RCC), which arises from renal epithelium, is the most common form of kidney cancer (1). Unfortunately, unlike other solid tumours, RCC is still refractory to standard cytotoxic chemotherapy and most patients eventually develop resistance after receiving one or more therapeutic agents (2). Thus, it is urgent to develop new and improved antitumor drugs, particularly drugs of natural origin.

Umbelliferone, also known as 7-hydroxycoumarin, is a polyphenolic component found in fruits, vegetables, roots of plants and flowers (e.g., golden apple, carrot, coriander, garden angelica, mouse-ear hawkweed and pharbitis nil) (3). It has multiple functions, such as antioxidant, antidiabetic and antitumor activities (4).

\footnotetext{
*Correspondence; e-mail: nbuurology@126.com
} 
Phosphoinositide 3-kinases (PI3Ks), a family of dual-specificity signalling enzymes (5), generate lipid second messengers that regulate different aspects of cell biology, such as cell growth, survival, motility and metabolism. Mammals have eight isoforms of PI3Ks, which have been divided into three classes, class I, II, and III PI3Ks. Thus far, class I PI3Ks are the best understood and most studied class because they are known to have a great effect on cancer (6). On the basis of a strong association with regulatory subunits, catalytic subunits of class I PI3Ks are subdivided into class IA and class IB PI3Ks. The only class IB PI3K member, p110 $\gamma$, binds to the regulatory subunit p101 rather than p85. Some evidence has shown that $\mathrm{p} 110 \gamma$ is also activated by G-proteins in the absence of p101 in vitro and in vivo (7). Unexpectedly, PI3K $\gamma$ signalling has been reported to activate C/EBP $\beta$ activation via mTor and Akt suppression of $\mathrm{NF} \kappa \mathrm{B}$ activation and subsequently promote immunosuppression during tumour growth and inflammation in mouse models of cancer (8). However, the role of the p110 $\gamma$ catalytic subunit of PI3K $\gamma$ in human cancer, particularly in human RCC, has yet to be identified. Therefore, the present study mainly aims to evaluate the cytotoxic potential of umbelliferone in vitro, using three human RCC cell lines, which enable the identification of umbelliferone and its effective inhibition of RCC by p110 $\gamma$.

\section{EXPERIMENTAL}

\section{Cell lines and cell culture}

786-O and ACHN cells (human RCC cell lines) were obtained from the American Type Culture Collection (USA). OS-RC-2 cells (human RCC cell line) were purchased from the Cell Bank of the Chinese Academy of Sciences, Shanghai, China. 786-O and OS-RC-2 cells were maintained in RPMI 1640 medium (HyClone, UT, USA) containing 10 \% FBS (Shanghai ExCell Biology, Inc., China). ACHN cells were maintained in Dulbecco's modified Eagle's medium (HyClone, USA) containing 10 \% FBS (Shanghai ExCell Biology, Inc., China). All cell lines were grown at $37^{\circ} \mathrm{C}$ in a humidified atmosphere and in the presence of $5 \% \mathrm{CO}_{2}$.

\section{MTS assay}

All cell lines were incubated in 96-well plates (Corning Inc., USA) at a density of $5 \times 10^{3}$ cells/well in RPMI-1640 or DMEM with $10 \%$ FBS. After $24 \mathrm{~h}$, the cells were incubated with $0,5,25,50,100$ or $150 \mu \mathrm{mol} \mathrm{L}-1$ of umbelliferone for $0,24,48$ or $72 \mathrm{~h}$ at $37^{\circ} \mathrm{C}$ in $5 \%$ of $\mathrm{CO}_{2}$. Next, $20 \mu \mathrm{L}$ of CellTiter $96^{\circledR}$ Aqueous One Solution Reagent (MTS, PROMEGA, USA) was added to each well and the samples were incubated at $37^{\circ} \mathrm{C}$ for $3 \mathrm{~h}$. After that, the absorbance was measured at $490 \mathrm{~nm}$ using a spectrophotometer (Thermo Multiskan GO, USA).

\section{Cell apoptosis detection by flow cytometry}

According to the manufacturer's instructions, cell apoptosis was tested using an Apoptosis Detection kit (AP101-30, MultiSciences (Lianke) Biotechnology Corporate Limited, China). Briefly, all cell lines were treated with $0,5,25,50,100$ or $150 \mu \mathrm{mol} \mathrm{L}^{-1}$ of umbelliferone. After $48 \mathrm{~h}$, cells $\left(1-5 \times 10^{5}\right.$ cells) were collected, washed with PBS, resuspended in $500 \mu \mathrm{L}$ of $1 \times$ Binding Buffer, and then stained with $5 \mu \mathrm{L}$ of Annexin V-FITC and $10 \mu \mathrm{L}$ of PI for 5 min in the dark, and subsequently analysed using a FACScan flow cytometer (BD Biosciences, USA). 


\section{Cell cycle analysis}

All cell lines were treated with a wide range of umbelliferone concentrations $(0,5,25$, 50, 100 or $150 \mu \mathrm{mol} \mathrm{L}^{-1}$ ) for $48 \mathrm{~h}$. Subsequently, the cell cycle was measured using a cell cycle detection kit (CCS012, MultiSciences (Lianke) Biotechnology Corporate Limited, China) according to the manufacturer's instructions. Briefly, cells $\left(2-10 \times 10^{5}\right.$ cells) were collected, washed with PBS, and stained with $1 \mathrm{~mL}$ of DNA staining solution and $10 \mu \mathrm{L}$ of permeabilization solution at room temperature for $30 \mathrm{~min}$; flow cytometric analysis was then performed by FACScan flow cytometry (BD Biosciences, USA).

\section{Western blot analysis}

Cultured cells were lysed and protein was extracted using High-efficiency RIPA lysis buffer (Solarbio, China) after umbelliferone treatment $\left(0,5,25,50,100\right.$ or $\left.150 \mu \mathrm{mol} \mathrm{L}^{-1}\right)$ as described above for $48 \mathrm{~h}$. Equal amounts of protein were loaded onto SDS-PAGE before transfer onto PVDF membranes (0.2 $\mu \mathrm{m}$, \#162-0177 Bio-Rad, USA). After blocking with $5 \%$ non-fat dry milk, the membranes were incubated with specific primary antibodies overnight at $4{ }^{\circ} \mathrm{C}$. The following antibodies were used: anti-MCM2 (\#12079), Cyclin E1 (\#20808), Bax (\#5023), Bcl-2 (\#15071), phosphoinositide 3-kinase p110 $\gamma$ (\#4252S), CDK2 (\#2546S), CDK4 (\#2906S), $\beta$-actin (\#8457), GAPDH (\#5174) (Cell Signaling Technology, USA, dilution 1:1,000), Cyclin D1 (PB0403) (Wuhan Boster Biological Technology, Ltd., China, dilution 1:1,000), and anti-Ki67 antibody (ab15580) (Abcam, UK, dilution 1:1,000). Secondary antibodies included goat anti-rabbit (BA1054) or goat anti-mouse (BA1050) IgG-HRP (Wuhan Boster Biological Technology, Ltd., China, dilution 1:5,000). Signals were detected by enhanced chemiluminescence (ECL) reagent (Beyotime). Densitometric analysis of proteins was performed using the Tanon GIS version 4.1.2 software (Tanon Science and Technology Co., Ltd., China).

\section{Statistical analysis}

Results were expressed as the mean \pm SD of three representative independent experiments. Statistical analysis was performed using one-way ANOVA with SPSS 18.0 software. $p<0.05$ was considered to be statistically significant compared to $0 \mu \mathrm{mol} \mathrm{L}-1$ umbelliferone.

\section{RESULTS AND DISCUSSION}

\section{Cytotoxic effect of umbelliferone against human RCC cells}

The effects of umbelliferone on the growth of human malignant cell lines in vitro have demonstrated umbelliferone as a potent cytotoxic and cytostatic agent and as a more potent derivative compared to coumarins (9).

To detect the effect of umbelliferone on human RCC, we first examined the changes in cell proliferation in human RCC cells treated with umbelliferone. As shown in Fig. 1, treatment of cells with umbelliferone at concentrations of 50, 100 and $150 \mu \mathrm{mol} \mathrm{L}^{-1}$ caused a gradual decrease in cell proliferation. This decrease continued following 48 and $72 \mathrm{~h}$ exposure, which appeared to be concentration-dependent. In addition, decreased cell pro- 

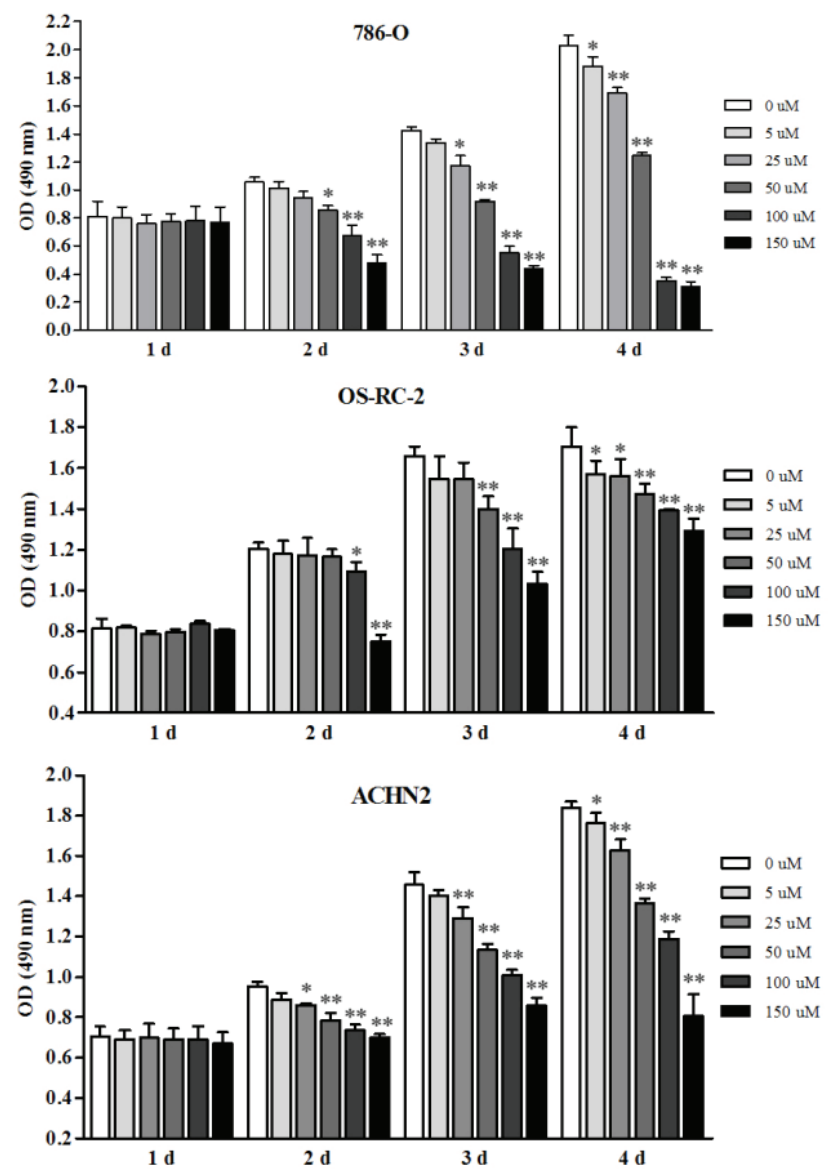

Fig. 1. 786-O, OS-RC-2 and ACHN cell proliferation after incubation with umbelliferone in a gradient concentration $\left(0-150 \mu \mathrm{mol} \mathrm{L}^{-1}\right)$ at $0,24,48$ and $72 \mathrm{~h}$. Data are presented as the mean $\pm \mathrm{SD}$ from three independent experiments. ${ }^{*} p<0.05,{ }^{* *} p<0.01$ vs. $0 \mu \mathrm{mol} \mathrm{L}^{-1}$ treatment.

liferation was observed in response to umbelliferone at the $72 \mathrm{~h}$ time-point in 786-O cells and at the 48 and $72 \mathrm{~h}$ time-points in ACHN cells, but no change was observed at the studied time-points in OS-RC-2 cells. These observations indicated that human RCC had a concentration-dependent effect in response to umbelliferone; however, the time dependence was not obvious.

\section{Umbelliferone increased cell apoptosis in human RCC}

Annexin V/FITC staining showed a clear induction of apoptosis in a dosedependent manner in 786-O, OS-RC-2 and ACHN cells. With an increase in umbelliferone concentration, the proportions of early apoptotic human RCC cells continuously increased (Fig. 2). 


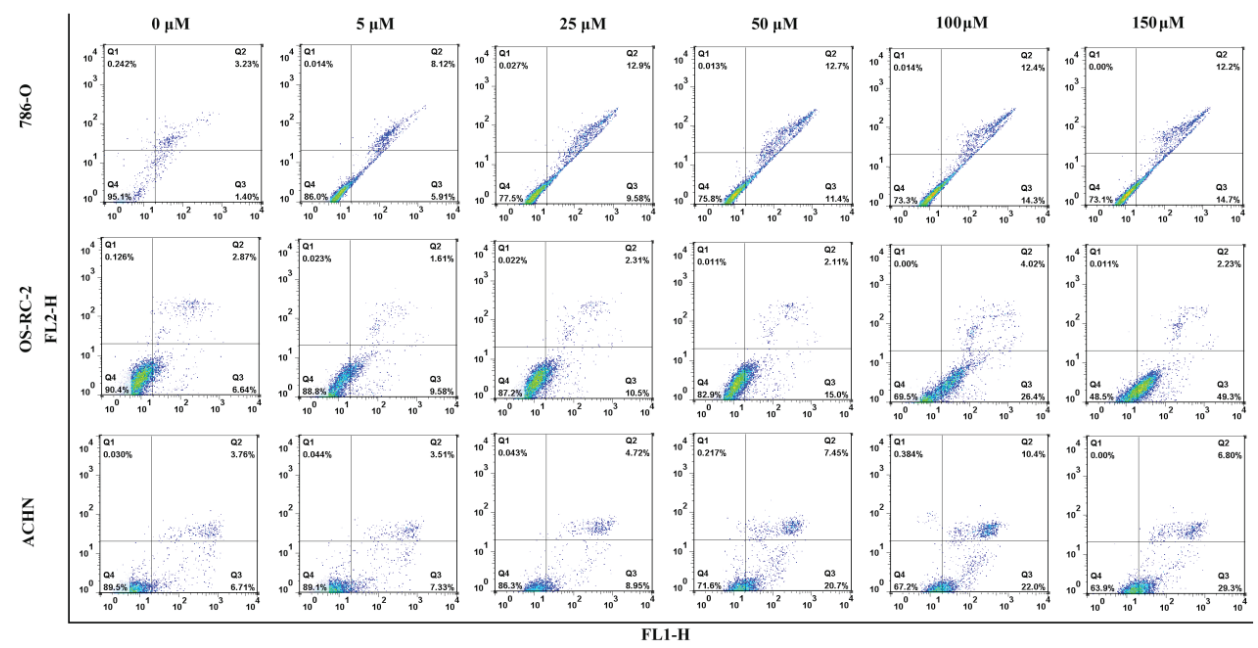

Fig. 2. 786-O, OS-RC-2 and ACHN cell apoptosis after $48 \mathrm{~h}$ incubation with 0, 5, 25, 50, 100 and 150 $\mu \mathrm{mol} \mathrm{L}{ }^{-1}$ of umbelliferone. Dot-plot of Annexin-V-fluorescein $v s$. PI, early apoptotic cells (\%) are localised in the lower right quadrant. Data are shown as the mean \pm SD from three independent experiments. ${ }^{*} p<0.05,{ }^{* *} p<0.01$ vs. $0 \mu \mathrm{mol} \mathrm{L} \mathrm{L}^{-1}$ treatment.

Umbelliferone also exhibited significant anticancer effects by inducing dose-dependent apoptosis in HepG2 cells (3). These results indicated that umbelliferone promoted cell apoptosis in cancer in a concentration-dependent manner.

\section{Umbelliferone arrested cell cycle in G1 phase in human RCC}

In addition, umbelliferone regulated cell death via DNA damage and arrest in the G0/ G1 phase of the cell cycle and had anticancer effects in a human oral carcinoma cell line (10). However, Jose Sullivan Lopez-Gonzalez et al. found that umbelliferone suppressed cell growth by arresting the cell cycle in the G1 phase, but the apoptosis of lung carcinoma cells was not related to intra-nucleosomal DNA fragmentation in all lung carcinoma cell lines (11). In the current study, we found that following an increase in umbelliferone concentration, the percentage of cells in the $S$ and G2 phases was gradually reduced and the proportion of cells in the G1 phase was continuously increased in 786-O, OS-RC-2 and ACHN cells (Fig. 3). Therefore, we proposed that umbelliferone induced G1 phase arrest in a variety of cancers and exerted an effect on their proliferation and apoptotic pattern.

\section{Umbelliferone induces the expression of proteins related to cell proliferation, apoptosis and cell cycle}

Moreover, umbelliferone decreased the expression of cyclin D1 protein in the human lung adenocarcinoma cell line A-427(12). An increase in Bax protein and a decrease in Bcl-2 protein were also observed in umbelliferone-pretreated A427 cells. Furthermore, C. M. Eli- 

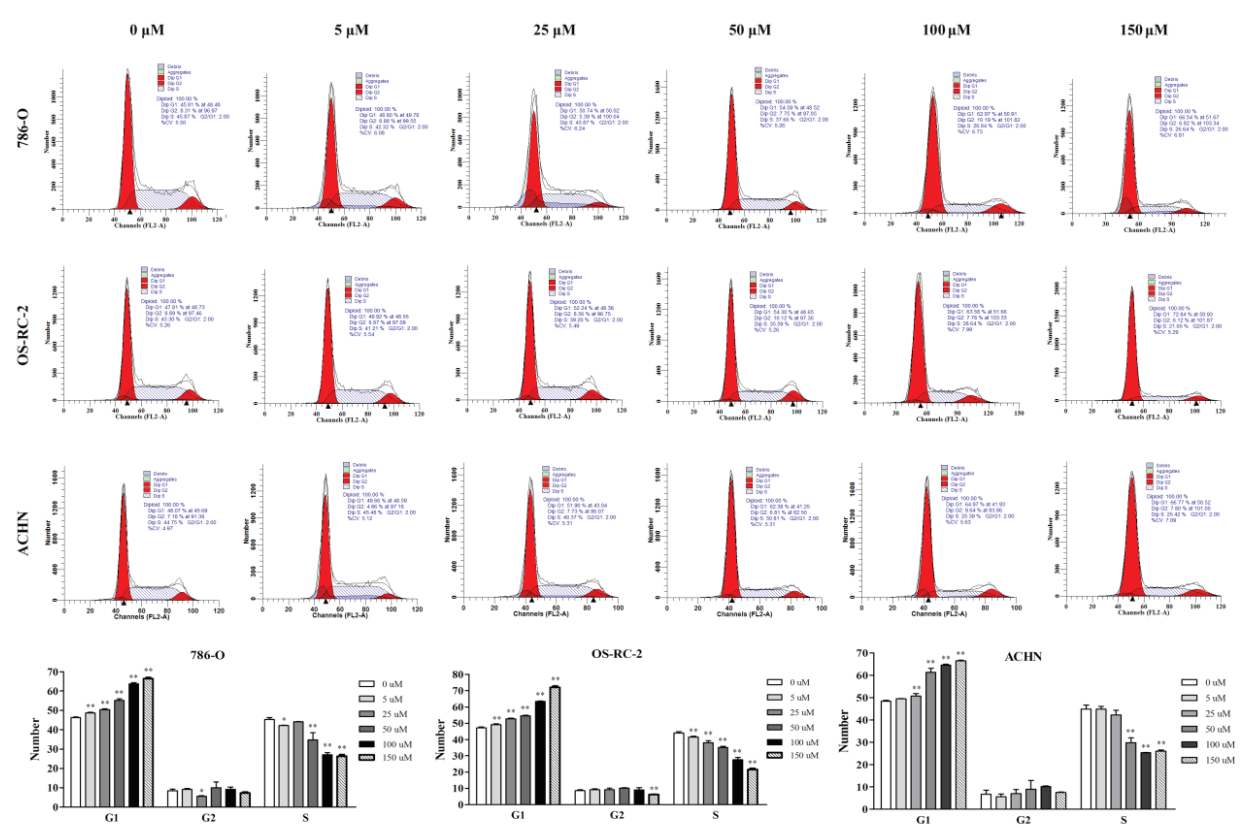

Fig. 3. Cell cycle distributions of umbelliferone treated 786-O, OS-RC-2 and ACHN cells with various concentrations $\left(0,5,25,50,100\right.$ and $\left.150 \mu \mathrm{mol} \mathrm{L}^{-1}\right)$ for $48 \mathrm{~h}$. Histograms indicate the number of the channel (horizontal axis) against DNA content (vertical axis). Data are shown as the mean \pm SD from three independent experiments. ${ }^{*} p<0.05,{ }^{* *} p<0.01$ vs. $0 \mu \mathrm{mol} \mathrm{L}^{-1}$ treatment.

nos-Ba et al. concluded that umbelliferone was a more potent inhibitor of cancer cell proliferation compared to coumarin and exhibited marked effects on oncoprotein expression (13). Thus, we detected expression of the proliferation biomarkers, Ki67 and MCM2; pro-apoptotic protein Bax; anti-apoptotic protein Bcl-2; and several key cell cycle control proteins, including CDK2, CyclinE1, CDK4, and CyclinD1, using western blotting analysis. It was clear that umbelliferone effectively up-regulated the expression of Bax protein and down-regulated the expression of Ki67, MCM2, Bcl-2, CDK2, CyclinE1, CDK4, and CyclinD1 protein compared to cells treated with $0 \mu \mathrm{mol} \mathrm{L} \mathrm{L}^{-1}$ umbelliferone, further confirming the inhibitory effect of umbelliferone on proliferation regulation, the enhanced effect of umbelliferone on apoptosis induction and the arrested effect of umbelliferone on cell cycle in the G1 phase (Fig. 4). With regard to these proteins, umbelliferone treatment resulted in a dose-dependent regulation in human RCC cells, which was consistent with the above results.

\section{P110 $\gamma$ contributes to umbelliferone-induced human RCC cell proliferation, apoptosis and cell cycle}

In normal cells, PI3Ks activity is closely controlled by internal signals, for example, PTEN, but it has been observed that the development of $1 / 3$ of human cancers is related to an imbalance of the PI3K signalling pathway (14). Researchers have found that inhibition 
$X$. Wang et al.: The antitumor activity of umbelliferone in human renal cell carcinoma via regulation of the p110 $\gamma$ catalytic subunit of PI3K $\gamma$, Acta Pharm. 69 (2019) 111-119.

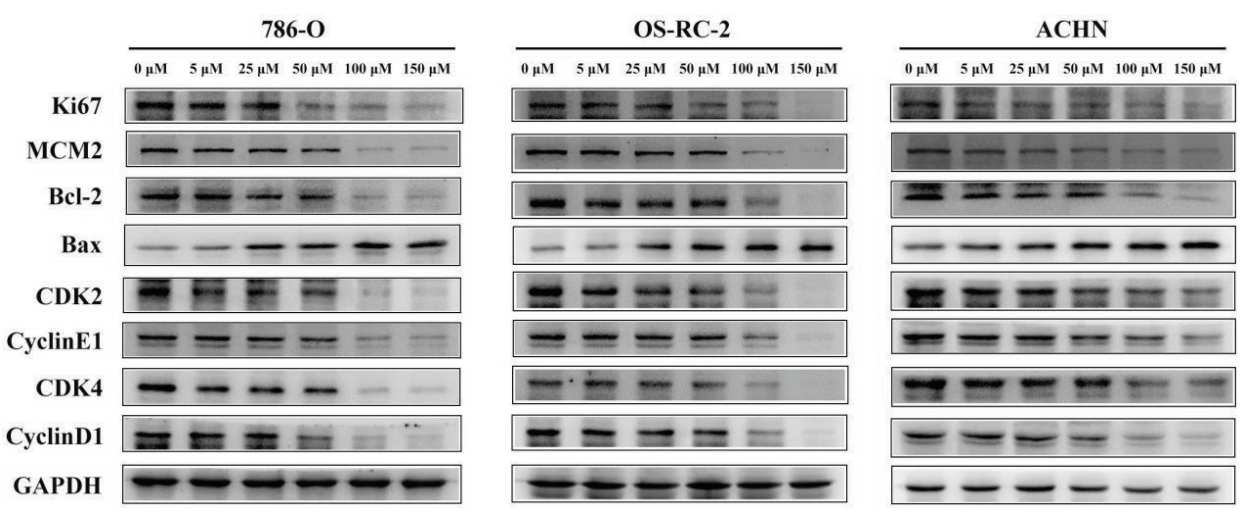

Fig. 4. Concentration-dependent inhibition of Ki-67, MCM2, Bcl-2, Bax, CDK2, CyclinE1, CDK4, CyclinD1 protein expression in 786-O, OS-RC-2 and ACHN cells by umbelliferone. Data are shown as the mean \pm SD from three independent experiments. ${ }^{*} p<0.05,{ }^{* *} p<0.01$ vs. $0 \mu \mathrm{mol} \mathrm{L}^{-1}$ treatment.

of PI3K expression enhanced Bcl-2-dependent apoptosis in RCC (15). To further explore whether p110 $\gamma$ has an important function in human RCC induced by umbelliferone, we observed the expression of p110 $\gamma$ protein.

a)
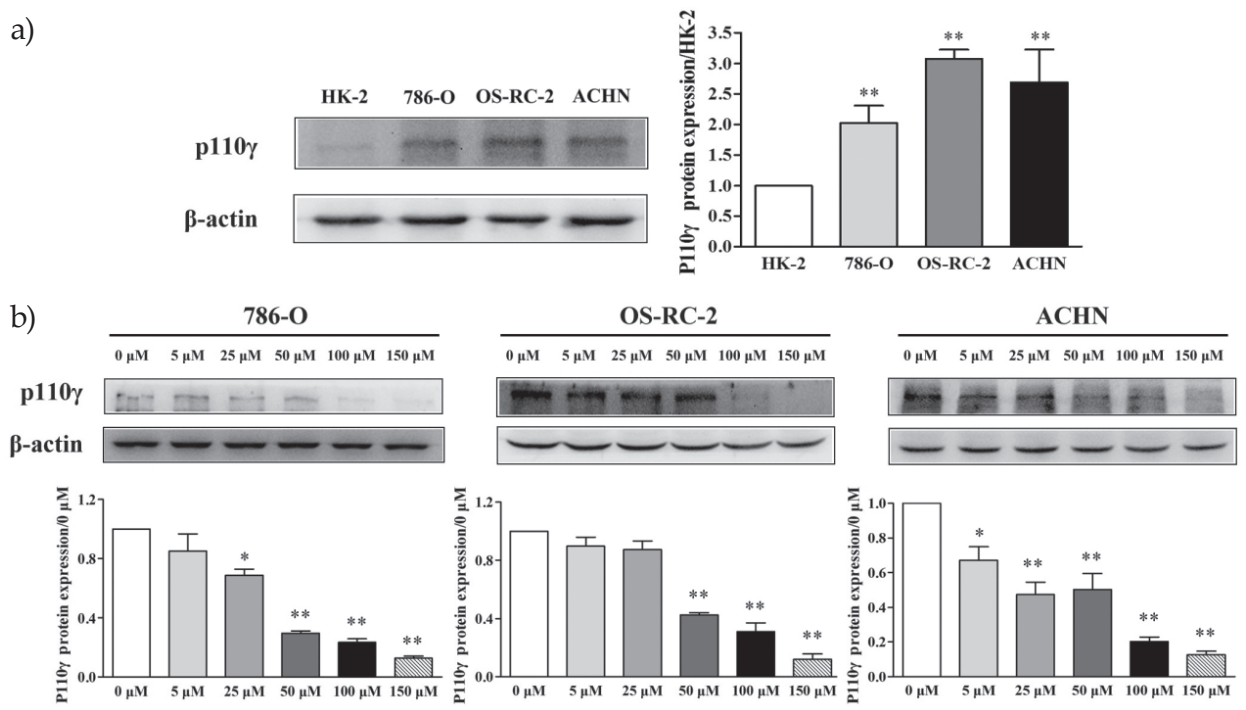

Fig. 5. Concentration-course inhibition of PI3K p110 $\gamma$ by umbelliferone in human RCC cells: a) Western blotting analyses were performed to detect the level of p110 $\gamma$ in human RCC cells and HK-2; b) 786-O, OS-RC-2 and ACHN cells were incubated with increasing concentrations of umbelliferone for $48 \mathrm{~h}$. p110 $\gamma$ protein expression levels were analysed by western blot using their corresponding specific antibodies. The same lysates were then probed for $\beta$-actin as a normalisation control. Data are shown as the mean \pm SD from three independent experiments. ${ }^{*} p<0.05,{ }^{* *} p<0.01 v s .0 \mu \mathrm{mol} \mathrm{L}^{-1}$ treatment. 
We found that the expression of p110 $\gamma$ was upregulated in human RCC cell lines, 786O, OS-RC-2 and ACHN, compared to HK-2 (Fig. 5a). Moreover, we observed a significant concentration-dependent decrease in p110 $\gamma$. At $50 \mu \mathrm{mol} \mathrm{L}^{-1}$, umbelliferone resulted in sustained inhibition in the expression of $\mathrm{p} 110 \gamma$ (Fig. 5b). This finding was consistent with umbelliferone-regulated Ki67, MCM2, Bax, Bcl-2, CDK2, CyclinE1, CDK4, and CyclinD1 expression in these cell lines.

\section{CONCLUSIONS}

Taken together, we propose that umbelliferone regulated the expression of proliferation-related proteins, apoptosis-related proteins and cell cycle control proteins via p110 $\gamma$ in human RCC cells and further regulated cell cycle arrest, inhibited tumour cell proliferation and induced apoptosis in vitro. In conclusion, the suppressive activity of umbelliferone in human RCC is mediated by p110 $\gamma$. Importantly, umbelliferone might be a potential medicine in the treatment of human RCC. However, p110 $\gamma$ most likely exhibits more complex mechanisms in its contribution to cancer and the function of p110 $\gamma$ requires further extensive study.

Acknowledgements. - This work was supported by grants obtained from the Scientific Plan of Medical and Health Planning of Zhejiang Province (grant nos. 2017187241 and 2018275380), Ningbo Natural Science Foundation (grant no. 2016A610018) and Planning Project of Medical Science and Technology of Ningbo (grant no. 2017A02).

\section{REFERENCES}

1. M. Song, Recent developments in small molecule therapies for renal cell carcinoma, Eur. J. Med. Chem. 142 (2017) 383-392; https://doi.org/10.1016/j.ejmech.2017.08.007

2. P. Mendiratta, B. I. Rini and M. C. Ornstein, Emerging immunotherapy in advanced renal cell carcinoma, Urol. Oncol. 35 (2017) 687-693; https://doi.org/10.1016/j.urolonc.2017.08.011

3. S. M. Yu, D. H. Hu and J. J. Zhang, Umbelliferone exhibits anticancer activity via the induction of apoptosis and cell cycle arrest in HepG2 hepatocellular carcinoma cells, Mol. Med. Rep. 12 (2015) 3869-3873; https://doi.org/10.3892/mmr.2015.3797

4. D. Li, N. Wang, J. Zhang, S. Ma, Z. Zhao and E. M. Ellis, Hepatoprotective effect of 7-hydroxycoumarin against methyl glyoxal toxicity via activation of Nrf2, Chem. Biol. Interact. 276 (2017) 203209; https://doi.org/10.1016/j.cbi.2017.02.020

5. A. Bondev, T. Bondeva and R. Wetzker, Regulation of phosphoinositide 3-kinase $\gamma$ protein kinase activity in vitro and in COS-7 cells, Signal Transduction 1 (2015) 79-85.

6. H. Guo, P. German, S. Bai, S. Barnes, W. Guo, X. Oi, H. Lou, J. Liang, E. Jonasch, G. B. Mills and Z. Ding, The PI3K/AKT Pathway and renal cell carcinoma, J. Genet. Genomics 42 (2015) 343-353; https://doi.org/10.1016/j.jgg.2015.03.003

7. U. Maier, A. Babich and B. Nurnberg, Roles of non-catalytic subunits in gbetagamma-induced activation of class I phosphoinositide 3-kinase isoforms beta and gamma, J. Biol. Chem. 274 (1999) 29311-29317.

8. M. M. Kaneda, K. S. Messer, N. Ralainirina, H. Li, C. J. Leem, S. Gorjestani, G. Woo, A. V. Nguyen, C. C. Figueiredo, P. Foubert, M. C. Schmid, M. Pink, D. G. Winkler, M. Rausch, V. J. Palombella, J. Kutok, K. McGovern, K. A. Frazer, X. Wu, M. Karin, R. Sasik, E. E. Cohen and J. A. Varner, PI3K $\gamma$ 
is a molecular switch that controls immune suppression, Nature 539 (2016) 437-442; https://doi. org/10.1038/nature19834

9. M. E. Marshall, K. Kervin, C. Benefield, A. Umerani, S. Albainy-Jenei, Q. Zhao and M. B. Khazaeli, Growth-inhibitory effects of coumarin (1,2-benzopyrone) and 7-hydroxycoumarin on human malignant cell lines in vitro, J. Cancer Res. Clin. Oncol. 120 Suppl. (1994) S3-10.

10. A. Vijayalakshmi and G. Sindhu, Umbelliferone arrest cell cycle at G0/G1 phase and induces apoptosis in human oral carcinoma (KB) cells possibly via oxidative DNA damage, Biomed. Pharmacotherapy 92 (2017) 661-671; https://doi.org/10.1016/j.biopha.2017.05.128

11. J. S. Lopez-Gonzalez, H. Prado-Garcia, D. Aguilar-Cazares, J. A. Molina-Guarneros, J. MoralesFuentes and J. J. Mandoki, Apoptosis and cell cycle disturbances induced by coumarin and 7-hydroxycoumarin on human lung carcinoma cell lines, Lung Cancer 43 (2004) 275-283; https://doi. org/10.1016/j.lungcan.2003.09.005

12. F. A. Jiménez-Orozco, J. S. López-González, A. Nieto-Rodriguez, M. A. Velasco-Velázquez, J. A. Molina-Guarneros, N. Mendoza-Patiño, M. J. García-Mondragón, P. Elizalde-Galvan, F. LeónCedeño and J. J. Mandoki, Decrease of cyclin D1 in the human lung adenocarcinoma cell line A-427 by 7-hydroxycoumarin, Lung Cancer 34 (2001) 185-194.

13. C. M. Elinos-Baez, F. Leon and E. Santos, Effects of coumarin and 7OH-coumarin on bcl-2 and Bax expression in two human lung cancer cell lines in vitro, Cell Biol. Int. 29 (2005) 703-708; https://doi. org/10.1016/j.cellbi.2005.04.003

14. A. Akinleye, P. Avvaru, M. Furqan, Y. Song and D. Liu, Phosphatidylinositol 3-kinase (PI3K) inhibitors as cancer therapeutics, J. Hematol. Oncol. 6 (2013) 88; https://doi.org/10.1186/1756-8722-6-88

15. S. Zhu, M. B. Cohen, J. D. Bjorge, J. W. Mier and D. C. Cho, PI3K inhibition potentiates Bcl-2-dependent apoptosis in renal carcinoma cells, J. Cell Mol. Med. 17 (2013) 377-385; https://doi. org/10.1111/jcmm.12019 